\title{
Epistemological closed questions: A reply to Greco
}

\author{
Charles Côte-Bouchard \\ Rutgers - State University of New Jersey \\ Department of Philosophy \\ New Jersey, USA \\ charles.cote79@gmail.com
}

Article info

CDD: 120

Received: 01.07.2017; Revised: 30.10.2017; Accepted: 20.11.2017

DOI: http://dx.doi.org/10.1590/0100-6045.2017.V40N4.CC

Keywords:

Metaepistemology

Epistemology

Metaethics

'Open question' argument

Epistemic normativity

\begin{abstract}
According to G.E. Moore's 'Open Question' argument (OQA), moral facts cannot be reduced or analyzed in non-normative natural terms. Does the OQA apply equally in the epistemic domain? Does Moore's argument have the same force against reductionist accounts of epistemic facts and concepts? In a recent article, Daniel Greco has argued that it does. According to Greco (2015), an epistemological version of the OQA is just as promising as its moral cousin, because the relevant questions in epistemology are just as 'open' as those in ethics. In this paper, I offer a two-part reply to Greco. First, I argue that his argument in favor of the openness of epistemology is not persuasive. Second, I offer a case against the openness of epistemology. Unlike claims linking natural and moral properties, claims linking natural and epistemological properties do give rise to closed questions. An epistemological OQA is therefore not as promising as its moral cousin.
\end{abstract}

\section{Introduction}

It has become commonplace for epistemologists to emphasize the normative character of their discipline. Epistemic facts and concepts, many argue, are inherently normative just like moral facts and concepts. ${ }^{1}$ If this is right, then one

\footnotetext{
${ }^{1}$ See, for instance, Sellars (1956), Kim (1988), Gibbard (1990), Kelly (2003), Cuneo (2007), Chrisman (2007), Ridge (2007), Street (2009), Grimm (2009), Rowland (2013), and Greco (2015).
}

Manuscrito - Rev. Int. Fil. Campinas, v. 40, n. 4, pp. 97-111, out.-dez. 2017. 
plausible consequence is that many questions and argument that traditionally belong to moral philosophy can be transposed to epistemology. This includes metaethical questions about the nature and existence of moral facts. One such question is whether moral facts and concepts can be reduced or analyzed in nonnormative natural terms. But if epistemic facts are no less normative than moral facts, then the same question plausibly arises in epistemology. Are epistemic facts and concepts unanalyzable and irreducible or can they be reduced or analyzed in non-normative natural terms?

In ethics, the most well-known argument against analytical or reductive naturalism is G.E. Moore's (1903) 'Open Question' argument (OQA). In a nutshell, Moore thought that moral facts and concepts are unanalyzable because for any non-normative natural properties $\mathrm{N}$, questions of the form ' $\mathrm{X}$ is good, but is it N?' are necessarily 'open' or substantive rather than 'closed' or trivial. ${ }^{2}$ Despite its prominence in ethics, however, the OQA has rarely been applied to epistemology. That is, few have defended or examined an open question argument against reductive analyses of epistemic facts and concepts.

One notable exception is Daniel Greco. ${ }^{3}$ In a recent article, Greco has offered a forceful and illuminating defense of the OQA in epistemology. According to him, an epistemological version of the OQA is just as promising as its moral cousin. This is because, he argues, claims linking natural and epistemological properties - natural/epistemological linking claims for short - give rise to open or substantive questions just like natural/moral linking claims. I will refer to this as Greco's openness thesis. In what follows, I offer a two-part reply to Greco. First, after briefly presenting the OQA and Greco's case for the openness thesis, I argue in sections 2 and 3 that his argument is not persuasive. I then offer a case against the openness thesis in section 4 . I argue that unlike natural/moral linking claims, natural/epistemological linking claims do give rise to closed questions. I therefore conclude that, pace Greco, an epistemological OQA is not as promising as its moral cousin.

\section{Greco's case for openness in epistemology}

\subsection{The 'Open Question' argument and Greco's openness thesis}

\footnotetext{
${ }^{2}$ I return to the OQA below.

${ }^{3}$ Greco (2015). Other notable exceptions include Jenkins (2007) and Heathwood (2009).
} 
What is Moore's 'Open Question' argument? According to Greco's interpretation, which I follow in this paper, the OQA is best seen as a two-step inference to the best explanation. The first step (the explanandum) is that claims linking natural and moral properties - natural/moral linking claims for short give rise to open or substantive questions. What makes a question open is, of course, controversial. But according to Greco's construal, which I will also follow, a question Q is open when, roughly, neither answering 'yes' nor 'no' to Q would count against one's having or mastering the concepts in Q. Conversely, Q is closed or trivial if failing to give a certain answer would count against one's possessing the concepts in Q. ${ }^{4}$

For example, 'George is an unmarried adult male, but is he a bachelor?' is closed since one's answering 'no' would count against one's having the concept of a bachelor. By contrast, if someone were asked ' $\phi$-ing maximizes overall wellbeing, but is $\phi$-ing morally right?', her answering 'no' would not plausibly count against her possessing or mastering the concept of moral rightness. She could, for instance, reject the utilitarian moral theory at issue in the question and she would not thereby lack the relevant moral concepts. It is therefore an open or substantive question and not a closed question.

The second step of the OQA is then to show that reductive analyses of moral concepts cannot explain why such questions are open and that a particular nonreductionist account is the one that best explains it. Like Greco, I will set aside this second step and focus on the first. According to Greco, this first step of the OQA is just as promising in epistemology as it is in ethics. Claims linking natural and epistemic properties - natural/epistemological linking claims for short - give rise to open or substantive questions just like natural/moral linking claims. Epistemology, in other words, is just as 'open' as ethics. This is what I will call Greco's openness thesis.

\subsection{An initial worry: correctness}

As Greco himself remarks, there is a fundamental disanalogy between epistemology and ethics, which presents a prima facie difficulty for the openness

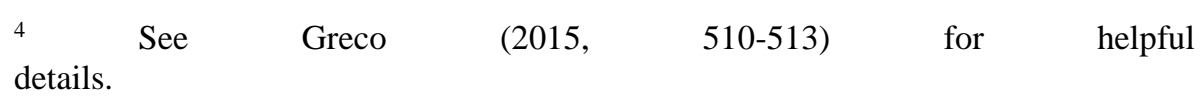


thesis. In epistemology, truth plays the fundamental role that the right or the good plays in ethics. But, as Greco explains:

[i]f ethics involves aiming at the right or the good, then a natural thought is that, in much the same sense, epistemology involves aiming at the true. But while questions about the relationship between natural properties and rightness or goodness seem open, questions about the relationship between natural properties and truth seem quite clearly closed. From the fact that the cat is on the mat - a natural fact - it straightforwardly follows that it's true that the cat is on the mat. Moreover, it plausibly counts against somebody's possessing the concept of truth if they accept the former, purely naturalistic, claim while denying the latter, truth-involving, one. (Greco 2015, 514)

If the fundamental 'aim' of epistemology - unlike the 'aim' of ethics - gives rise to closed questions, doesn't this cast prima facie doubt on the idea that epistemology is just as 'open' as ethics?

Greco's reply to this worry forms the basis of his case in favor of the openness thesis. Even if truth plays this fundamental role in epistemology, he points out, epistemologists qua epistemologists are not interested in which beliefs are in fact true. Rather, they are interested in which beliefs merit positive epistemic evaluation. But since a belief's epistemic evaluation is not a matter of whether it is in fact true, the 'truth versus good' disanalogy alone poses no problem for the openness thesis. Moreover, and most importantly, Greco argues that natural/epistemological linking claims do give rise to open questions like natural/moral linking claims.

Before examining Greco's case for this thesis, it is worth mentioning one initial problem with his response to the disanalogy. Even if we accept that the actual truth of a belief is logically independent from whether it is epistemically justified, rational, or reasonable ${ }^{5}$, Greco omits the notion of correctness. To call a belief 'correct', at least from an epistemic standpoint ${ }^{6}$, is plausibly to give it a

${ }^{5}$ Although see Sutton (2007), Littlejohn (2012), and Williamson (Forthcoming) for the thesis that beliefs are not epistemically justified unless they are true.

${ }^{6}$ As opposed to 'correct' from a non-epistemic standpoint such as that of morality, prudence, aesthetics, and so on. It might be coherent to claim, for instance, that a false (and thus epistemically incorrect) belief is nevertheless the correct one to have from a moral, prudential, or aesthetic standpoint. 
positive epistemic evaluation and therefore to make a genuine epistemic claim. The notion of correctness, in other words, is plausibly part of epistemology's 'turf.

Yet, whether a belief is correct does have to with whether it is in fact true. If this is true, then Greco's openness thesis already faces a problem since claims linking naturalistic properties and correctness do give rise to closed questions. Here are two examples:

(a) P is true, but is S's belief that P correct, epistemically speaking?

(b) P is false, but is S's belief that P incorrect, epistemically speaking?

The answer to (a)-(b) is, trivially, 'yes'. Once we find out that a proposition $\mathrm{P}$ is true or false, it is not a substantial or open question whether the belief that $\mathrm{P}$ is correct and whether anyone who believes that $\mathrm{P}$ is correct, at least from an epistemic standpoint. Someone's failing to answer 'yes' to (a)-(b) would plausibly count against her possessing the concept of epistemic correctness for belief. So if attributions of epistemic correctness are positive epistemic evaluations, then we have an example of a kind of natural/epistemological linking claims that give rise to closed questions and which therefore casts doubt on the openness of epistemology.

One could respond by arguing that correctness is not a genuinely or intrinsically normative notion. ${ }^{7}$ After all, the sole fact that $\phi$-ing counts as correct relative to some standard might not automatically imply that there is a genuinely normative reason for you to $\phi .^{8}$ There might be no normative reason for you to conform to that standard in the first place. So perhaps the closedness of (a) and (b) is simply due to the fact that correctness is not a genuinely normative notion in the first place.

But the problem with this response is that whether or not they are intrinsically normative, the correctness claims in (a) and (b) are still epistemological claims. To call a belief correct is still plausibly to give it a positive epistemic evaluation. But if this is right, then the problem remains: natural/correctness linking claims are still natural/epistemological linking claims that give rise to closed questions.

\footnotetext{
${ }^{7}$ Thanks to an anonymous referee for raising this possible response.

${ }^{8}$ See e.g. Gibbard (2005) and Hattiangadi (2007). I also discuss this issue in CôtéBouchard (2016).
} 


\subsection{Greco's case for the openness of epistemology}

Let us set this worry aside, however, and return to Greco's case in favor of the openness thesis. To show that epistemology is just as 'open' as ethics, Greco considers what he sees as the most promising kind of strategy against the openness thesis (and in favour of metaepistemological reductionism) and argues that it cannot succeed. The reductionist strategy he outlines is what I will call the chance-based strategy.9 That strategy starts with the idea that claims linking high objective chance and reasons to believe (or as Greco puts it, reasons to be confident) give rise to closed or trivial questions such as:

(CR) P has a high objective chance, but do I have any reason to be confident that P?

The strategy is that even though chance is a naturalistic notion, CR is not an open question. My denying that I have any reason to be confident in $\mathrm{P}$ given that $\mathrm{P}$ has a high objective chance would count against my possessing the concepts in CR. If this is right, then we have a clear example of a kind of natural/epistemological linking claim which, unlike natural/moral linking claims, give rise to closed questions. An epistemological OQA is therefore not as promising as its moral cousin.

According to Greco, this chance-based reductionist strategy is vulnerable to a fatal dilemma. Accounts of objective chance can either be normative or nonnormative. Objective chance, in other words, is either a straightforwardly nonnormative naturalistic notion or a covertly normative notion. The problem, he argues, is that the chance-based strategy collapses either way. If chance is normative, then although CR will be closed, its closedness will provide no support for metaepistemological reductionism since the goal of reductionism is to reduce epistemic properties to non-normative naturalistic properties. This is what I will call the normative horn of the dilemma. If chance is a non-normative notion, then the chance-based strategy also fails, according to Greco, because CR thereby becomes an open question. I will refer to this second horn of the dilemma as the non-normative horn.

To illustrate the openness of CR on the non-normative horn, Greco uses Lewis's (1973) 'Best Systems' account of laws and chance. According to this

\footnotetext{
${ }^{9}$ Such a strategy can be attributed to Heathwood (2009).
} 
account, very roughly, chance laws are whatever would result from a certain exercise in curve fitting - i.e. an exercise in finding the best tradeoff between strength in matching frequencies and simplicity - under certain idealized circumstances. ${ }^{10}$ On this account then, to say that $\mathrm{P}$ has an objective chance $n$ to happen just is to say that the idealized curve-fitter would predict that $\mathrm{P}$ would happen with degree of confidence $n$. But the problem, according to Greco, is that one could very well admit the non-normative fact that this would be the curvefitter's prediction and still coherently deny that she ought to have the same credence in P. ${ }^{11}$ Thus on the normative horn, questions arising from chance/epistemological linking claims like CR are bound to be open questions. Therefore, the chance-based strategy against the openness thesis collapses on the non-normative horn as well.

I will do two things in the rest of this paper. In the next section, I will argue that Greco's objection against the chance-based strategy is not persuasive. Reductionists who invoke chance/epistemological linking claims against the openness thesis need not be troubled by the dilemma that Greco outlines. Then in section 4, I will offer a case against the openness thesis. I will argue that an epistemological OQA is not as promising as its moral cousin because natural/epistemological linking claims do, in fact, give rise to closed questions.

\section{Responding to Greco's dilemma}

\subsection{Epistemology's turf}

As Greco rightly points out, epistemologists qua epistemologists are interested in which beliefs merit positive epistemic evaluations. What he does not mention, however, is that epistemologists are therefore not interested in just any kind of justification, rationality, reasonableness, reasons, and 'oughts'. In particular, it is not part of the epistemologist's job description to tell us what is non-epistemically (e.g. morally, prudentially, aesthetically, legally, and so on) or all-things-considered justified, rational, and reasonable. Rather, the epistemologist's job is to tell us what is epistemically justified, epistemically

${ }^{10}$ See Greco (2015, 518-519) for details.

11 Where 'coherently' means without that denial counting against her having the relevant epistemic concepts. 
rational, and epistemically reasonable. Similarly, the epistemologist qua epistemologist is not concerned with non-epistemic (e.g. moral, prudential, aesthetic, legal, etc.) reasons and oughts, but rather with epistemic reasons and epistemic 'oughts'.

Consequently, the starting point of the chance-based strategy should not be $\mathrm{CR}$, but rather:

(CER) P has a high objective chance, but do I have any epistemic reason to be confident that P?

This clarification puts the chance-based strategy on stronger intuitive footing. Even if you are not convinced that CR is closed, it is hard to see how one could coherently deny that one has any epistemic reason to be confident that $\mathrm{P}$ while acknowledging that there is a high objective chance that P. After all, what else could mark reasons for belief as epistemic (as opposed to e.g. prudential, moral, and so on) if not a connection with truth, which the presence of a high objective chance indicates? The question, therefore, is whether a chance-based strategy that starts from CER faces Greco's dilemma.

\subsection{The non-normative horm}

According to Greco, the chance-based strategy fails if objective chance is construed non-normatively because it makes CR (or CER) open. As explained above, Greco illustrates this using the best-system account of objective chance. His point is that, as he puts it, "one might coherently fail to have a conditional credence of $\mathrm{n}$ in $\mathrm{P}$, given that the curve-fitter's systematization entails that $\mathrm{P}$ has a chance of n." (Greco 2015, 520)

A first thing to note is that at this stage, Greco has shifted to a different natural/epistemological linking claim. In CR and CER, the subject does not ask whether she ought to have a degree of belief $n$ given that $\mathrm{P}$ has a chance of $n$. Rather, she asks whether she has any epistemic reason to be confident that $\mathrm{P}$ if $\mathrm{P}$ has a high objective chance. Therefore, the important question given the bestsystems account is whether one could coherently deny that she has any epistemic reason to be confident that $P$, given that the curve-fitter's systematization entails that $\mathrm{P}$ has a high chance. That is, is the following question open or closed? 
(CERBS) The curve-fitter's systematization entails that $\mathrm{P}$ has a high objective chance, but do I have any epistemic reason to be confident that P?

The right answer, I would suggest, is 'it depends'. In particular, it depends if you accept the best-systems account of chance.

If you reject it, then it can be coherent for you to deny that you have any epistemic reason to be confident that P. You could deny, for instance, that the curve-fitter's systematization really entails anything about P's objective chances. But this alone would not count against the closedness of CER since your answer would not be due to a rejection of the linking between high objective chance and epistemic reasons. Instead, it would be due to your rejection of the link between the idealized curve-fitter's prediction and high objective chance.

If you accept the best-systems account of chance, then for the same reasons that CER seems closed, it is hard to see how you could coherently answer 'no' to CERBS. If you think that objective chances just are what the curve-fitter's systematization entails - and consequently, that there really is a high chance that $\mathrm{P}$ is true - then it is unclear why CERBS would seem any less closed or trivial than CER. If you accept the best-system account, then for you to answer 'no' to CERBS amounts to your answering 'no' to CER.

This response generalizes to any non-normative account of chance according to which P's having a high objective chance just is for $\mathrm{P}$ to have some nonnormative naturalistic property NN. For any such account, the chance-based reductionist can always say that if (i) one accepts that account - i.e. if she accepts that to have the property NN just is to have a high objective chance - and (ii) one agrees that $\mathrm{P}$ has $\mathrm{NN}$, then she cannot coherently maintain that she does not have any epistemic reason to be confident that P. Given one's acceptance of the non-normative account, one's denying that one has any such epistemic reason would simply amount to her answering 'no' to CER. Therefore, the nonnormative horn is not, after all, fatal to the chance-based strategy against the openness thesis. The chance-based reductionist can maintain that chance is nonnormative without giving up the closedness of CER.

At this point, one might object that if we accept that an epistemic reductionist could use this move, then a moral reductionist could use the same kind of move with the same plausibility in response to a moral OQA. But if this is right, then my treatment of the non-normative horn poses no real problem for Greco's 
larger thesis, namely that OQAs in epistemology and in ethics are on equal footing. To see this, consider the following question:

(MAX) Performing action X would maximize overall well-being, but is it the morally right thing to do?

Is MAX open? According to proponents of the moral OQA, it is. But couldn't a moral reductionist reply 'it depends if you accept act-utilitarianism'? That is, couldn't she respond that it might be coherent to say 'no' if you reject utilitarianism, but not if you accept it? ${ }^{12}$

These two moves are not analogous and do not have the same plausibility, however. My reply to the non-normative horn - on behalf of the chance-based strategist - is that one could reply 'it depends' to the openness of CERBS. But in the present context, MAX is not the equivalent of CERBS, but of CER. The chance-based reductionist strategy starts with the claim that CER is a closed question. And on the non-normative horn, the chance-based strategist adds that objective chance is a non-normative notion. CERBS only comes at a later stage, after we have adopted a particular non-normative account of objective chance. And it is only at that later stage that the 'it depends' move enters the picture.

In the moral case, the equivalent strategy, in response to a moral OQA, would be to start with the claim that MAX is a closed question and that well-being is a non-normative property. The equivalent of CERBS (and the 'it depends' move) would come at a later stage, after having adopted a particular non-normative account of well-being. Clearly, however, such a strategy in response to the moral OQA would not have the same plausibility as the chance-based strategy. It would depend on the closedness of MAX. But unlike CER, MAX is clearly not a closed question. Therefore, my response to Greco's non-normative horn does not mean that a moral reductionist could use the same kind of move with the same plausibility against a moral OQA.

\subsection{The normative horn}

What if objective chance is a normative notion? I agree with Greco that in that case, the closedness of CER alone would not be problematic for the openness thesis. This, however, does not mean that this horn would be fatal to

12 Thanks to an anonymous referee for raising this objection.

Manuscrito - Rev. Int. Fil. Campinas, v. 40, n. 4, pp. 97-111, out.-dez. 2017. 
the reductionist who is counting on chance judgments to reject the openness thesis.

If chance is a normative notion, then it is presumably an epistemological normative notion like e.g. that of what credence it would be epistemically rational to have under certain idealized circumstances. But even if that is the case, the reductionist could still respond by invoking closedness at the level of claims linking naturalistic properties and objective chance. That is, the chance-based strategy would remain viable if natural/objective chance linking claims also gave rise to closed questions. Such additional closed questions would help the reductionist and count against the openness thesis since those would be cases of closed questions arising from natural/epistemological linking claims.

And, crucially, it does seem like natural/objective chance linking claims give rise to closed questions. Here are some examples:

(c) $\mathrm{P}$ is necessarily false, but is there any chance that $\mathrm{P}$ ?

(d) $\mathrm{P}$ is necessarily true, but is there any chance that not-P?

(e) $P$ is true and $P$ entails $Q$, but is it there any chance that not-Q?

One's failing to answer 'no' to (c)-(e) would plausibly count against one's having the concept of chance. Therefore, although it forces her to amend her strategy, Greco's normative horn does not appear to be fatal to the chance-based reductionist. If chance judgments are normative epistemic judgments, then she can still fall back on closed questions arising from natural/objective chance linking claims to challenge the openness thesis.

\section{Closedness in epistemology: against the openness thesis}

I have argued that Greco's main case for the openness thesis is not persuasive: his dilemma is not fatal to reductionists who pursue the chance-based strategy. Of course, this conclusion alone does not mean that the chance-based strategy succeeds or that the openness thesis is false. For all I said so far, the chancebased strategy might still fail and an epistemological OQA might still turn out to be just as promising as its moral cousin.

In the rest of this paper, I would like to briefly bolster the case against the openness thesis by offering examples of closed questions that arise from different kinds of natural/epistemological linking claims. These are claims that involve 
naturalistic properties and epistemic justification, rationality, and reasonableness. Here are two examples:

(f) $\mathrm{S}$ believes a falsehood $\mathrm{P}$ only because $\mathrm{S}$ wants $\mathrm{P}$ to be true and what $\mathrm{S}$ wants to be true is almost never true, but is S's belief that P epistemically justified/rational/reasonable?

(g) S believes a falsehood $\mathrm{P}$ only because she heard it from someone who always lies and $\mathrm{S}$ believes truly that her informant always lies, but is S's belief that $\mathrm{P}$ epistemically justified/rational/reasonable?

The answer to $(\mathrm{f})-(\mathrm{g})$ is, trivially, 'no'. It is not a substantial or open question whether S's belief is epistemically justified, rational, or reasonable in (f)-(g). One's failing to answer 'no' would plausibly count against one's possessing these distinctly epistemic concepts.

Note that we can get the same result with epistemic 'oughts'. In particular, (f) $-(\mathrm{g})$ remain closed or trivial if we replace 'is S's belief that P epistemically justified/rational/reasonable?' with 'does $\mathrm{S}$ believe as she ought, epistemically speaking?' Failing to respond 'no' to those reformulated questions would plausibly count against one's having the concept of the epistemic 'ought'.

A final kind of natural/epistemological linking claims that give rise to closed questions is one that Greco himself brings up. He admits that natural/epistemological linking claims do give rise to closed questions when those claims involve one proposition entailing the other or its negation. But this, he claims, is just a special kind of case that does not affect the prospects of an epistemological OQA. It is, in other words, a harmless exception that poses no problem for the openness thesis. The following passage summarizes Greco's argument for treating those closed questions as harmless exceptions:

Why the restriction to cases in which neither propositions entails the other or its negation? Certainly, without it, our claim would be vulnerable to counterexample. 'Susan is six feet tall, but ought I to believe that she is more than five feet tall?' is clearly closed. [...] Ultimately, however, I don't think that the need for this restriction tells us much of interest about epistemological OQAs. [...] In general, when P obviously entails Q, ${ }^{\mathrm{P}}$, but Q?' will be closed. It seems to me that the correct explanation of this phenomenon is likely to generalize to provide an explanation of why, when P obviously entails $\mathrm{Q}$ (or its negation), questions of the form 'P, but 
ought I to believe Q?' are likewise closed. And I don't see any reason to think that, whatever the explanation is, it is likely to be threatening to OQAs. (Greco 2015, 521)

A first thing to note is that the questions Greco mentions to illustrate this point are not actually closed. The following are plausibly open:

(h) Susan is six feet tall, but ought I to believe that she is more than five feet tall?

(i) P is true, P obviously entails Q, but ought I to believe Q?

Someone's failing to answer 'yes' to these questions would not obviously count against her possessing the concept of doxastic 'ought' ('ought to believe'). She could very well judge, for instance, that despite the truth of these propositions, she ought not to believe them because doing so would have horrible consequences for herself and others. Or she could answer something like 'well, it depends from which point of view; are we asking if I ought to believe it epistemically speaking, morally speaking, prudentially speaking, all-thingsconsidered?' This, however, would not count against her having the concept of the doxastic 'ought'.

Plausibly however, those questions do become closed once we, as epistemologists, restrict our focus to the epistemic 'ought'. That is, although (h)-(i) are open, the following are not:

$\left(h^{*}\right)$ Susan is six feet tall, but ought I to believe that she is more than five feet tall, epistemically speaking?

(i*) P is true, P obviously entails Q, but ought I to believe Q, epistemically speaking?

Answering 'no' to $\left(\mathrm{h}^{*}\right)-\left(\mathrm{i}^{*}\right)$ would plausibly count against one's having the concept of the epistemic ought.

Greco's claim in the passage above is that the closedness of (h)-(i) will have an explanation that won't cause any problem for the openness thesis. In particular, he suggests that such an explanation will plausibly flow from the 
explanation of the fact that when P entails Q, 'P, but Q?' will be closed. As we have seen however, the closedness of (h)-(i) is not what needs to be explained since these questions are actually open. Rather, what needs to be explained is the fact that $\left(b^{*}\right)-\left(i^{*}\right)$ are closed while (b)-(i) are not. However, it is far from clear that an explanation of that fact will simply flow from the explanation of why 'P entails Q, P, but Q?' is closed. After all, an explanation of the latter will be silent on the contrast between epistemic and non-epistemic 'oughts'. It won't tell us what it is about epistemic 'oughts' that makes them follow trivially from naturalistic premises like those in $\left(h^{*}\right)-\left(i^{*}\right)$ unlike non-epistemic 'oughts'. For this reason, Greco's treatment of cases like (h)-(i) - and $\left(\mathrm{h}^{*}\right)-\left(\mathrm{i}^{*}\right)$ - as harmless exceptions is not warranted. Therefore, $\left(h^{*}\right)-\left(i^{*}\right)$ do constitute further examples of closed questions that cast doubts on an epistemological OQA.

In sum, since natural/epistemological linking claims do give rise to closed questions and since Greco's case in favor of the openness thesis is not persuasive, I conclude that contrary to what Greco argues, an epistemological OQA is not as promising as its moral cousin.

\section{References}

Chrisman, M. "From Epistemic Contextualism to Epistemic Expressivism." Philosophical Studies 135 (2): 225-254, 2007.

CÔTÉ-BOuCHARD, C. "Can the Aim of Belief Ground Epistemic Normativity?" Philosophical Studies 173: 3181-3198, 2016.

CuneO, T. 2007. The Normative Web: An Argument for Moral Realism Oxford University Press, 2007.

GibBard, A. Wise Choices, Apt Feelings: A Theory of Normative Judgment Harvard University Press, 1990.

"Truth and Correct Belief." Philosophical Issues 15 (1): 338-350, 2005.

Greco, D. "Epistemological Open Questions." Australasian Journal of Philosophy 93 (3): 509-523, 2015.

GrIMM, S. "Epistemic Normativity." In Epistemic Value, edited by Adrian Haddock, Alan Millar, and Duncan Pritchard, 243-264: Oxford: Oxford University Press, 2009.

Manuscrito - Rev. Int. Fil. Campinas, v. 40, n. 4, pp. 97-111, out.-deæ. 2017. 
HatTiangadi, A. Oughts and Thoughts: Rule-Following and the Normativity of Content. Oxford University Press, 2007.

Heathwood, C. "Moral and Epistemic Open-Question Arguments." Philosophical Books 50 (2): 83-98, 2009.

JEnkins, C. S. "Epistemic Norms and Natural Facts." American Philosophical Quarterly 44 (3): 259 - 272, 2007.

KELLY, T. "Epistemic Rationality as Instrumental Rationality: A Critique." Philosophy and Phenomenological Research 66 (3): 612-640, 2003.

KIM, J. "What is Naturalized Epistemology?" Philosophical Perspectives 2: 381-405, 1988.

LEWIS, D. Counterfactuals. Oxford: Basil Blackwell, 1973.

LiTTLEjOHN, C. Justification and the Truth-Connection Cambridge University Press, 2012.

MoOre, G. E. Principia Ethica Dover Publications, 1903.

RidgE, M. "Expressivism and Epistemology: Epistemology for Ecumenical Expressivists." Aristotelian Society Supplementary Volume 81 (1): 83-108, 2007.

SELLARS, W. S. "Empiricism and the Philosophy of Mind." Minnesota Studies in the Philosophy of Science 1: 253-329, 1956.

StReEt, S. "Evolution and the Normativity of Epistemic Reasons." Canadian Journal of Philosophy 39 (sup1): 213-248, 2009.

SuTTON, J. “Stick to what You Know." Nô̂s 39 (3): 359-396, 2005.

Williamson, T. Forthcoming. "Justifications, Excuses, and Sceptical Scenarios." In The New Evil Demon Problem, edited by Fabian Dorsch and Julien Dutant: Oxford University Press. 